\title{
Pyridoxine-dependent epilepsy
}

INSERM

\section{Source}

INSERM. (1999). Orphanet: an online rare disease and orphan drug data base. Pyridoxinedependent epilepsy. ORPHA:3006

Pyridoxine-dependent epilepsy (PDE) is a rare neurometabolic disease characterized by recurrent intractable seizures in the prenatal, neonatal and postnatal period that are resistant to anti-epileptic drugs (AEDs) but that are responsive to pharmacological dosages of pyridoxine (vitamin B6). 